\title{
¿Rebeldes sin causa? Caballeros templarios y los límites de Insurgencia Criminal*
}

\author{
Rebels without a cause? \\ Knights Templar and the criminal insurgency's limits \\ Esteban Arratia Sandoval ${ }^{* *}$ \\ Academia Nacional de Estudios Políticos y Estratégicos
}

Recibido: 16 de diciembre de 2016. Aprobado: 13 de septiembre de 2017

\section{Resumen}

Producto de la complejización y expansión de la violencia criminal durante la Guerra contra el narcotráfico, ha surgido un debate sobre la necesidad de resignificar el concepto insurgencia para aplicarlo al contexto mexicano, particularmente a Los Caballeros Templarios, un grupo criminal cuyo modus operandi se asemeja al utilizado por rebeldes. Sin embargo, ¿Los Caballeros Templarios representan un nuevo tipo de insurrección? Este trabajo pretende responder dicha interrogante, analizando y contrastando el comportamiento de ese cartel con los principales elementos teóricos de la insurrección: motivación, apoyo popular, uso de la violencia; y sujeto de mediación.

Palabras claves: guerra contra el narcotráfico, insurgencia criminal, Caballeros Templarios.

\footnotetext{
El presente artículo está basado en “insurgencia Criminal?: La cambiante naturaleza del crimen organizado transnacional en México y Centroamérica”, publicado en Estudios de Seguridad y Defensa № 5, junio 2015, pp. 39-82. Es un producto del Proyecto IN201503, “ ¿Tropas en la calle? Fuerzas Armadas en seguridad pública en México y El Salvador: Una visión comparada”, financiado por la Academia Nacional de Estudios Políticos y Estratégicos (ANEPE).

** Magíster en Estudios Internacionales, Universidad de Santiago. Investigador asociado de la Academia Nacional de Estudios Políticos y Estratégicos (ANEPE). Correo electrónico: jarratia@anepe.cl
} 


\begin{abstract}
As a product of the ever-increasing complexity and expansion of criminal violence during the War on Drugs, a debate has arisen on the need to redefine the concept of insurgency in its use in the Mexican context, particularly with the Caballeros Templarios (or Knights Templar), a criminal group whose modus operandi resembles those used by the rebels. However, do the Knights represent a new type of insurgency? This work seeks to answer this question analyzing and contrasting the behavior of this cartel with the main theoretical elements of the insurgency: motivation, popular support, use of violence and subject of mediation.Keywords: war on drugs, criminal insurgency, Knights Templar.
\end{abstract}

\title{
1. Aproximación teórica
}

En octubre de 2013, Los Caballeros Templarios lanzaron bombas de fabricación casera a dieciocho plantas eléctricas y seis estaciones de servicio en varias ciudades de todo el estado de Michoacán, provocando que más de 420.000 residentes perdieran el servicio de energía (Cawley, 2013). Probablemente, en este tipo de escenas pensaba la ex secretaria de Estado Hillary Clinton cuando declaró ante el Council on Foreign Relations que algunas organizaciones criminales mexicanas estaban "mostrando cada vez más indicios de insurgencia", hasta el punto de afirmar que el país se veía "cada vez más como Colombia hace 20 años, donde los narcotraficantes controlaban ciertas partes del territorio" (Carroll, 2010).

Los comentarios de Clinton no solo apuntan a una confusión sobre la naturaleza del conflicto que se desarrolla en México, sino también parecen ser reflejo de las discusiones dominantes en altas esferas gubernamentales y determinados círculos académicos estadounidenses, los cuales producto de la complejización y expansión del crimen organizado transnacional durante la Guerra contra el narcotráfico, plantean la necesidad de resignificar el concepto insurgencia a objeto de aplicarlo al contexto mexicano, particularmente a Los Caballeros Templarios, cuyo modus operandi se asemeja al utilizado por rebeldes. Sin embargo, cabe preguntarse, ¿este grupo criminal representa un nuevo tipo de insurrección?

158 Si Somos Americanos. Revista de Estudios Transfronterizos 
Como se aprecia en la tabla 1, ha surgido un debate entre dos corrientes de pensamiento basadas en supuestos mutuamente excluyentes sobre el carácter y evolución de los grupos criminales operativos en el país durante la última década.

TABLA 1

Debate Crimen Organizado Transnacional vs. Insurgencia Criminal en México

\begin{tabular}{ccc}
\hline & $\begin{array}{c}\text { Crimen Organizado } \\
\text { Transnacional }\end{array}$ & Insurgencia Criminal \\
\hline Paradigma de Seguridad & $\begin{array}{c}\text { Moderno (Estado-céntrico/ } \\
\text { Realismo) }\end{array}$ & $\begin{array}{c}\text { Postmoderno (Actores no } \\
\text { estatales) }\end{array}$ \\
\hline Paradigma de Insurgencia & $\begin{array}{c}\text { Ninguno (insurgencia está } \\
\text { basada solo en referentes } \\
\text { políticos. Ej. Maóismo) }\end{array}$ & $\begin{array}{c}\text { Insurgencia está basada en } \\
\text { criminalidad violenta }\end{array}$ \\
\hline Carteles como... & $\begin{array}{c}\text { Crimen Organizado/ } \\
\text { Crimen Organizado } \\
\text { Transnacional }\end{array}$ & $\begin{array}{c}\text { Nuevos "Hacedores de } \\
\text { guerra"/War Making } \\
\text { (Desafían al Estado) }\end{array}$ \\
\hline Miembros de carteles & $\begin{array}{c}\text { Empresarios violentos } \\
\text { (Ilícitos) }\end{array}$ & $\begin{array}{c}\text { Soldados criminales } \\
\text { (Insurgentes criminales) }\end{array}$ \\
\hline Foco del esfuerzo & $\begin{array}{c}\text { Mercados hipercompetitivos } \\
\text { (llícitos) }\end{array}$ & $\begin{array}{c}\text { Creación de enclaves } \\
\text { criminales } \\
\text { (Áreas de impunidad) }\end{array}$ \\
\hline Nivel de politización & Ninguno & $\begin{array}{c}\text { De facto (Libre de influencia } \\
\text { estatal) }\end{array}$ \\
\hline $\begin{array}{c}\text { Entorno de amenaza } \\
\text { Principal destinatario de } \\
\text { violencia }\end{array}$ & $\begin{array}{c}\text { Crimen de alta intensidad } \\
\text { (No es amenaza directa/ } \\
\text { ubicua a integridad del } \\
\text { Estado) }\end{array}$ & $\begin{array}{c}\text { Conflicto de baja } \\
\text { intensidad(Amenaza directa } \\
\text { a integridad del Estado) }\end{array}$ \\
\hline $\begin{array}{c}\text { Grupos rivales } \\
\text { hay insurgencia en } \\
\text { efecto) }\end{array}$ & $\begin{array}{c}\text { Instituciones/agentes } \\
\text { estatales }\end{array}$ \\
\hline
\end{tabular}

Fuente: Elaboración propia a partir de Bunker, 2013.

Por un lado, existe una visión modernista enmarcada en un paradigma de seguridad que adhiere al realismo. Cabe recordar que uno de los principios fundamentales promovidos por esa escuela es que solo los Estados son capaces de desafiar efectivamente a otros Estados, mientras que otros actores no estatales, como los carteles mexicanos, son 
incapaces de representar una amenaza directa a la seguridad nacional (Baylis, Wirtz y Gray, 2015, p. 384).

Según esta aproximación, el crimen organizado carece de cualquier tipo de base política, $y$, por lo tanto, es incapaz de comprometerse en una insurgencia con referentes político-ideológicos como por ejemplo el maoísmo (Sendero Luminoso). Dentro de esta perspectiva, carteles como Los Caballeros Templarios son concebidos como empresarios violentos que focalizan sus esfuerzos en mercados (ilícitos) hipercompetitivos, oponiéndose a organizaciones criminales rivales. Asimismo, instituciones y agentes estatales no son el destinatario principal de la violencia de actores criminales, tratándose más bien de una criminalidad de alta intensidad cuyo entorno genera batallas que no son una amenaza oblicua a su integridad (Bunker, 2013, pp. 31-32).

Por otro lado, es posible distinguir una visión postmodernista del fenómeno situada en un paradigma de seguridad que adhiere a un cambio de época post-Guerra Fría. Este enfoque plantea que grupos criminales como Los caballeros Templarios pueden efectivamente desafiar al Estado, al igual que una insurrección. Abogando por esta nueva aproximación sobre la criminalidad organizada, encontramos a Killebrew y Bernal (2010), quienes en Guerras del crimen: pandillas, carteles y la seguridad nacional estadounidense sostienen que esta ha hecho "metástasis en una nueva insurgencia que amenaza a los gobiernos del Hemisferio Occidental y, cada vez más, a Estados Unidos” (p. 5).

Bajo esa lógica, Sullivan (2012) utiliza el neologismo Insurgencia Criminal (Criminal Insurgency) que considera más apropiado para definir esta nueva dimensión alcanzada por la criminalidad organizada. Caracterizándola como un fenómeno híbrido que no se define a partir de su naturaleza política, como es usual en el empleo del término, sino en cuanto al desafío que representa para la capacidad regulatoria gubernamental. Difiriendo así de la concepción tradicional, pues la única motivación de esta "nueva" clase de rebeldía sería crear enclaves criminales a objeto de asegurar la libertad de maniobra para llevar a cabo sus ilícitos, convirtiéndose en una amenaza directa a la integridad del Estado. En otras palabras, la Insurgencia Criminal restringe la legitimidad gubernamental al anular su control territorial, capacidad de respuesta y recursos.

Manwaring (2008) va más allá, sosteniendo que los motivos comerciales ilícitos de las organizaciones criminales transnacionales están convirtiéndose en una agenda política nefasta, tornándose irrelevante que sea específicamente un grupo insurgente o criminal. De esa manera, su análisis sugiere que la base de la Insurgencia Criminal es la economía ilícita, la obtención de ganancias ocupa el lugar que en el concepto tradicional le pertenece 
a lo político-ideológico. En relación con este último aspecto, el periodista británico Ioan Grillo, autor de El Narco Inside Mexico's Criminal Insurgency, sostuvo durante una conversación con El País: "Lo que tenemos hoy en México es una rebelión armada sin ideología que combate al Estado [...] son grupos armados formados por la delincuencia organizada dirigidos por caudillos del crimen, caudillos postmodernos, que combaten al Estado" (Prados, 2012).

En este sentido, Bunker (2014) plantea que, pese a la ausencia de factores ideológicos, la Insurgencia Criminal en el caso mexicano constituye simultáneamente un fenómeno político y paramilitar. Político, en cuanto a su decisión de enfrentar abiertamente a los agentes estales para preservar sus negocios; y paramilitar porque a objeto de conseguir ese cometido, las organizaciones criminales echan mano a verdaderos ejércitos privados altamente especializados y equipados, incluso mejor que las propias Fuerzas Armadas. Por tal razón, Grillo (2012) postula que el proceso evolutivo de los carteles mexicanos hacia la categoría de insurgentes criminales radica en que sus motivaciones definen en muchos aspectos lo que son. O sea, si matan a civiles deliberada e intencionalmente, entonces se comportan como terroristas. En cambio, si tratan de poseer el monopolio de la violencia en determinado territorio, actúan como señores de la guerra (warlords). Y por último, si están librando una guerra total contra el gobierno, muchos alegarían que operan como rebeldes.

En relación con lo anterior, se ha planteado la existencia de tres etapas evolutivas en el mundo de los carteles mexicanos, tal como se observa en tabla 2. 
TABLA 2

Fases evolutivas de cárteles mexicanos

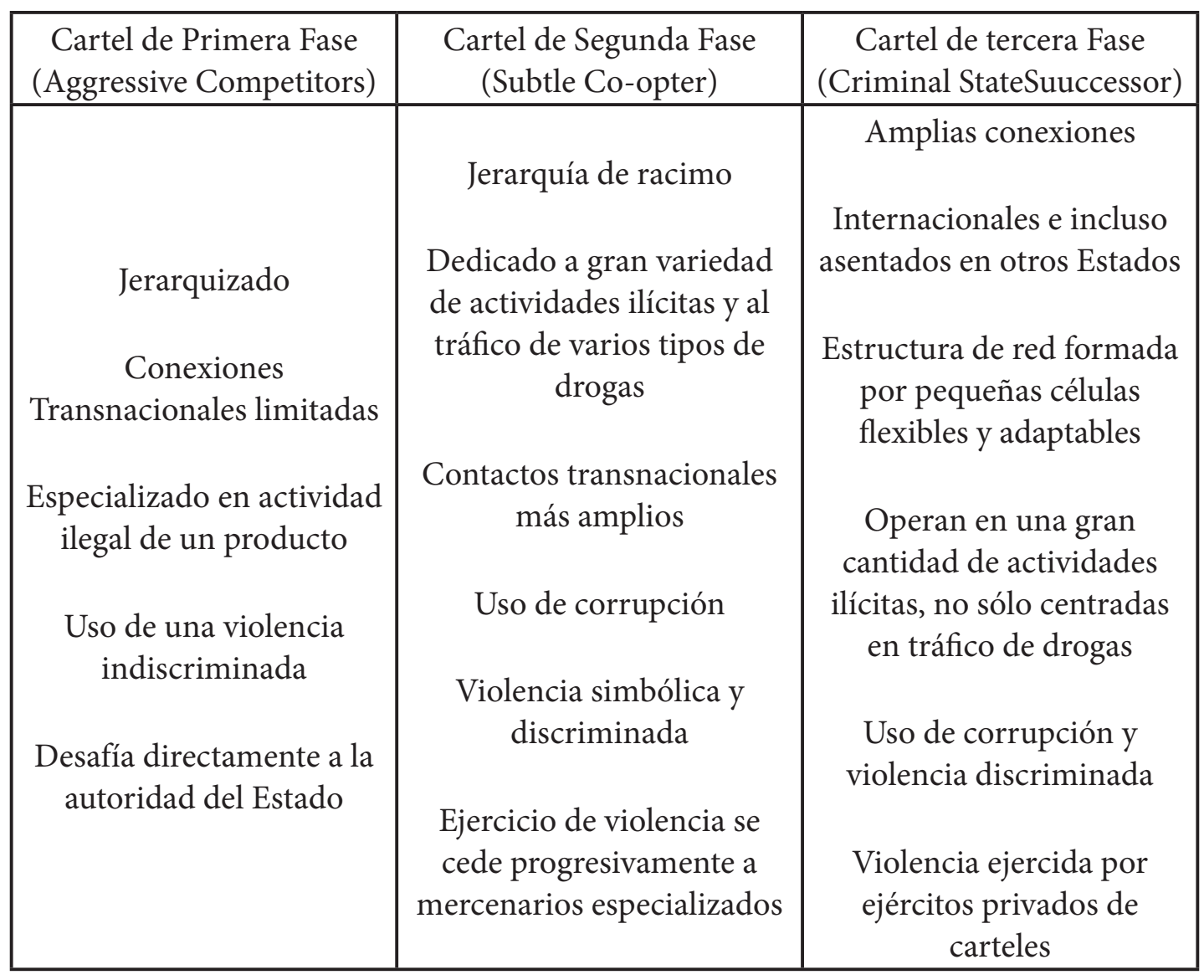

Fuente: Elaboración propia a partir de Bunker y Sullivan, 2010.

Los carteles de primera generación (Aggressive competitors) son competidores agresivos del Estado, con conexiones transnacionales limitadas; y especializados en la actividad ilegal de un producto, altamente violentos, jerarquizados y dispuestos a desafiar directamente la autoridad del Estado. En tanto, aquellos de segunda generación (Subtle Co-opter) tienen una estructura de racimo compuesta por diversas células dedicadas a una gran variedad de actividades ilícitas y al tráfico de varios tipos de droga, cuyos vínculos transnacionales son más amplios, y prevalece el uso de la corrupción por encima 
de la violencia, que adquiere un cariz más simbólico y discrecional (Bunker y Sullivan, 2010, pp. 11-12).

Por último, los carteles de tercera generación (Criminal State Successor) se caracterizan por sus amplios nexos internacionales, una estructura en red formada por pequeñas células flexibles y adaptables. Operan en una gran variedad de actividades ilícitas y utilizan la corrupción y violencia indiscriminada. Esta violencia es ejercida por ejércitos privados $y$, en algunos casos, estos brazos armados se convierten en organizaciones criminales independientes, como Los Zetas con relación al Cartel del Golfo.

Sin embargo, resta precisar que del cartel de tercera generación surgen dos subcategorías distinguidas por la forma de lograr sus objetivos. La primera es el cartel político, que utiliza la corrupción para someter a la autoridad política, en vez de competir directamente con ella por el poder. Es decir, son resultado de la corrupción sistemática del Estado, constituyendo una amenaza para el mismo al presentarse como Estados Sucesores Criminales. Mientras que la segunda subcategoría, el cartel insurgente criminal, busca crear enclaves criminales bajo su dominio y control en los cuales el poder del Estado desaparezca a través de la violencia e intimidación (Bunker y Sullivan, 2010, pp. 1213), subcategoría que se apega bastante al concepto Insurgencia Criminal entregado inicialmente.

\section{Condicionantes michoacanos y el germen templario}

El estado de Michoacán, localizado al suroeste de México, presenta un nivel de rezago mayor al resto del país. Se calcula que $59,2 \%$ de su población vive en pobreza y $14 \%$ en pobreza extrema (CONEVAL, 2015). El índice de desarrollo humano de este estado, en 2015 estaba entre los más bajos de la nación, solo por encima de Chiapas, Oaxaca y Guerrero (PNUD, 2015, p. 6).

La presencia del crimen organizado en territorio michoacano ha sido continua, pudiendo ser rastreada desde 1940. Diversas variables favorecieron el desarrollo del narcotráfico en dicho estado. Su clima y extensas serranías mal comunicadas propiciaron el cultivo de marihuana y amapola, sobre todo en el área conocida como Tierra Caliente, ofreciendo a su población rural pobre una opción económica más atractiva que los cultivos tradicionales de subsistencia (Maldonado, 2014). 
Durante las siguientes cuatro décadas, el cultivo y comercio de drogas se desenvolvieron con tranquilidad al amparo de las instituciones corruptas que, esporádicamente, erradicaron algunos plantíos y arrestaron a algunos criminales para simular un esfuerzo contra el narcotráfico. Luego, en 1980, un grupo criminal local conocido como El Cartel de Los Valencia dominó el territorio de Michoacán controlando el cultivo de marihuana y el tráfico de cocaína, utilizando el puerto Lázaro Cárdenas para ingresar drogas sintéticas al país (Rodríguez, 2015, pp. 24-25).

A fines de 1990 el panorama cambió, Los Zetas llegaron a la zona instalándose con relativa facilidad, pues Los Valencia no opusieron mucha resistencia frente a la superioridad militar de su rival. Además, ya existía un conflicto interno dentro de Los Valencia, que fue aprovechado por Los Zetas. El centro de operaciones de estos últimos estaba en Apatzingán, pero se expandieron rápidamente por todo el estado. Su modus operandi fue el mismo que en otras regiones: comenzaron a extorsionar a los habitantes, matando a aquellos que se negaban a pagarles (Valdés, 2013, pp. 272-273). Modalidad que rompió el antiguo equilibrio de poder entre los narcotraficantes y las comunidades michoacanas, basado en relaciones de convivencia e interés mutuo.

Luego, en 2006, nació el grupo conocido como La Familia Michoacana, que en principio tenía como objetivo expulsar a Los Zetas de la región y detener sus abusos, tachándolos de invasores. Este nuevo cartel era dirigido por Nazario Moreno González, alias El Chayo, y alcanzó un grado de independencia respecto a sus competidores que le permitió controlar el mercado en Michoacán (Finnegan, 2010).

Originalmente, La Familia contó en el apoyo de ciertos sectores sociales que los vieron como libertadores al haber expulsado a Los Zetas, pero luego el grupo comenzó a aplicar el mismo esquema extorsivo contra la población civil. En 2011, el cartel sufrió un quiebre y surgieron Los Caballeros Templarios, tras una feroz batalla por el poder en la zona, estos últimos desplazaron a La Familia. Los vencedores se caracterizaron por reafirmar el respeto a la población civil tal como su antecesor. Sin embargo, pronto montaron un sistema de control de los habitantes basado en la amenaza y violencia (Valdés, 2013, pp. 274-278). Tanto es así que, incluso subvirtieron las libertades básicas de los michoacanos, cobrando cuotas por adquirir un automóvil, llevar a los hijos a la escuela o comprar un kilo de tortillas (Proceso, 2013).

164 Si Somos Americanos. Revista de Estudios Transfronterizos 


\section{3. ¿Los Caballeros Templarios bajo un paradigma insurreccional?}

Los planteamientos señalados con anterioridad adquieren enorme relevancia en razón de que deconstruyen y resignifican el concepto insurgencia. No obstante, la utilización del término insurgencia usualmente posee un determinado significado, aunque no siempre uniforme en la literatura especializada.

En Delimitación teórica de la insurgencia: conceptos, fines y medios, Javier Jordán conceptualiza la insurrección como "actor, o un conjunto de actores, que se enfrentan de manera organizada y prolongada en el tiempo a la autoridad política establecida[...], mediante una estrategia efectiva de movilización social y con un empleo sustantivo de la fuerza" (2012, p. 4). Siguiendo esa línea, Counterinsurgency Field Manual 3-24 la concibe como "un conflicto político-militar organizado y prolongado, diseñado para debilitar el control y legitimidad de un gobierno establecido, que ocupa el poder $u$ otra autoridad política mientras aumenta el control de los insurgentes" (Guindo, 2013, p. 290).

Tal interpretación es refrendada por Reseña Analítica del Conflicto de Baja Intensidad (RACBI, por sus siglas en inglés), al expresar que "si se la considera como un desafío a la legitimidad política, la insurgencia plantea una amenaza directa y abierta para el ordenamiento de la sociedad y naturaleza del gobierno" (Sohr, 2015, p. 5).

Bajo esa lógica, la Guía de Análisis de Insurgencias utilizada por Central Intelligence Agency define el término como toda "actividad político-militar prolongada dirigida a obtener el control parcial o total de los recursos de un país a través del uso de fuerzas militares irregulares y organizaciones políticas ilegales" (Guindo, 2013, p. 292).

Incluso, Metz (2012) establece tres características propias del fenómeno:

- Terrorismo utilizado para promover inseguridad entre la población y obligarla a acercarse al movimiento para solicitar protección.

- Intentos multifacéticos para cultivar apoyo de la población general, a menudo socavando al nuevo régimen.

- Ataques contra el Gobierno. 
Como puede observarse, al margen de sus múltiples conceptualizaciones, existen axiomas que generan consenso en torno al significado de la insurrección como un fenómeno esencialmente político. De ese modo, la adopción del enfoque Insurgencia Criminal no ha concitado apoyo unánime en la comunidad académica pues, desde una perspectiva más reciente, aun cuando organizaciones criminales como Los Templarios apelen a tácticas similares utilizadas por rebeldes, equiparar ambos actores armados no estatales implicaría ignorar los principales elementos teóricos de la insurrección, tal como se desarrolla a continuación:

\subsection{Motivación}

La diferencia fundamental entre insurrecciones y grupos criminales organizados atañe a la finalidad que justifica la existencia de ambos actores no estatales. No existe una definición universalmente aceptada sobre lo que significa crimen organizado por tratarse de un fenómeno multifacético. E incluso, pese a ejercer una gran influencia institucional, ni siquiera la entregada por la Convención de Palermo ha logrado resolver las dudas sobre la delimitación entre lo que se considera crimen organizado y otras formas de asociación ilícita de menor rango ${ }^{1}$. Sin embargo, basándose en diversas conceptualizaciones existentes, Sánchez Escobar (2015) ha sistematizado los siguientes rasgos:

- $\quad$ Organización con cúpula de mando.

- Jerarquía con modelo de sofisticación.

- Especialización criminal.

- Objetivos de lucro en áreas financieras o dominación política.

- Utilización de sofisticada logística.

- Transnacionalidad directa o vínculos transnacionales.

1 De ese modo, en su artículo $2^{\circ}$ define crimen organizado como "un grupo estructurado de tres o más personas que exista durante cierto tiempo y que actúe concertadamente con el propósito de cometer uno o más delitos graves [...] con miras a obtener, directa o indirectamente, un beneficio económico u otro beneficio de orden material" (ONUDD, 2004, p. 5).

166 Si Somos Americanos. Revista de Estudios Transfronterizos 
- Niveles de disciplina, fungibilidad de miembros inferiores y distribución de roles.

- Capacidad de corrupción, penetración y vinculación con centros de poder estatal.

De la tabla anterior es posible inferir que su propósito es económico, siendo difícil aceptar la existencia de grupos criminales que busquen el poder político, excepto para corromperlo, comprarlo y realizar exitosamente sus negocios. Los delincuentes están motivados por el beneficio personal, en cambio la insurgencia es básicamente altruista pues tratar de lograr un bien mayor. En esa misma línea, Phillips (2015) asegura que existen dos clases de incentivos particularmente relevantes: materiales e intencionales. Los primeros son "básicamente financieros y otros beneficios tangibles, mientras que los segundos son recompensas intangibles que se derivan del sentido de la satisfacción de haber contribuido a la consecución de una buena causa" (p. 239).

El crimen organizado depende principalmente de incentivos materiales para desarrollar sus ilícitos. En contraposición, las insurrecciones pueden sumar adherentes exclusivamente en función de incentivos intencionales, como su interés en apoyar la causa. De hecho, los incentivos son de suma importancia para entender cómo la decapitación de las organizaciones puede interrumpir la provisión de incentivos a sus miembros (ver tabla 3). Diferencias que resultan críticas al momento de explicar por qué la aplicación de una estrategia High Value Target afecta de manera contraproducente a los carteles en comparación a grupos insurgentes (Arratia, 2015).

TABLA 3

Incentivos/Mercado Insurgencia vs. Crimen Organizado Transnacional

\begin{tabular}{ccc}
\hline & Insurgencia & $\begin{array}{c}\text { Crimen Organizado } \\
\text { Transnacional }\end{array}$ \\
\hline Incentivos para miembros & Intencionales (Intangibles) & Materiales (Tangibles) \\
\hline "Mercado" & Ideas/Opinión pública & Economías Ilícitas \\
\hline
\end{tabular}

Fuente: Elaboración propia a partir de Phillips, 2015.

Desde ese ángulo, cabe precisar que ningún cartel mexicano ha declarado formal o unilateralmente la guerra al Estado, no están entre sus planes intentar derrocar algún 
gobierno, ni tampoco pretenden instalar su propia administración, solo les basta con debilitar $\mathrm{u}$ obstruir el accionar gubernamental para enfrentarlas. No obstante, los grupos criminales a menudo representan trampas de gobernabilidad, comportándose de alguna manera como insurrectos pues, aunque el crimen organizado es en gran medida un fenómeno económico, también puede asumir un importante rol institucional y transformarse en proveedor no solo de oportunidades económicas, sino también regulador de la estructura social de comunidades enteras, ofreciendo múltiples bienes y servicios públicos a la población en aquellas áreas donde ostenta gran poder y su presencia es más significativa (DCAF, 2012).

Bajo esa lógica, Grillo (2016) utiliza el neologismo caudillos criminales (gangster warlords), que considera más apropiado para definir la hibridez de líderes criminales caracterizados por configurar una presencia simultánea (concurrent presence), controlando ciertos territorios y amenazando la naturaleza fundamental del Estado, no tratando de tomárselo por completo sino usurpando algunas de sus funciones y debilitándolo, operando en su lugar. Con frecuencia se inmiscuyen en el monopolio estatal de la violencia o, más precisamente, en el monopolio de la guerra y administración de justicia. De tal manera, protegen las fronteras de sus dominios, asesinan a enemigos armados que entran a su territorio, cobran vacunas, realizan juicios, respaldan a los políticos y desarrollan trabajos sociales.

Por tal razón, la criminalidad organizada acaba construyendo legitimidad a través de relaciones complejas y mutuamente beneficiosas con las comunidades donde opera a objeto de utilizar un territorio disponible para desarrollar su economía ilícita. Brinda bienes y servicios valiosos que el Estado no ofrece, la creación de demanda, producción y distribución de los mismos requiere protección armada, pero este respaldo a menudo se extiende a (o es demandado por) comunidades locales para afianzar dichos vínculos. En efecto, el apoyo de la comunidad resulta vital para la supervivencia de grupos criminales, en particular con el fin de evitar que información se filtre a las autoridades.

En otras palabras, la participación estratégica de estos actores no estatales afecta el propósito fundamental del Estado y tiene implicaciones políticas, pues actúan como constructores competitivos de Estado, mermando su funcionalidad y legitimidad. De ese modo, mientras más orden, seguridad y bienes económicos brinden para ganarse las mentes y corazones de la población local, mayor es la posibilidad de convertirse en protoestados de facto con un alto grado de capital político gracias a la aceptación y legitimidad de los residentes en función de asegurar que toleren, o en algunos casos, 
prefieran a estos grupos por encima del Estado, e incluso se nieguen a cooperar con él, reduciendo su capacidad de respuesta (Felbab-Brown, 2013).

Ahora bien, en México operan algunas organizaciones criminales que exhiben ciertos rasgos de protoinsurgencia, como Los Caballeros Templarios, "pretendiendo dominar la vida política de la comunidad, controlar su capacidad para organizarse e interactuar con el Estado, determinar el alcance y funciones de los gobiernos locales y a veces incluso ejercer un cuasi-control sobre el territorio local" (Cardash y Cilluffo, 2008, p. 12).

Lo cierto es que este cartel se encuentra a medio camino entre el crimen organizado y la insurgencia, pero más cerca del primer término que al segundo.

En ese sentido, Aguilar Camín (2015) sostiene que este grupo criminal introduce

una forma de control territorial inexistente hasta entonces. De su modus operandi derivará un método de captura criminal de gobiernos locales y, como consecuencia de ésta, una captura de la sociedad local, mediante diversas formas de amedrentamiento, control social, despojo, secuestro y un sistema de pago de cuotas y derechos que envidiaría el sistema impositivo de cualquier Estado. Constituyéndose en el eslabón último del crimen organizado, el lugar donde habría que dejar de llamarlo crimen pues empieza a ser otra cosa: una especie de propietario sustituto del Estado, en particular de sus formas municipales.

Siendo posible afirmar que Los Caballeros Templarios han logrado construir un proyecto de gobernanza alternativa mediante la provisión de un grado mínimo de orden social o ley fáctica. Vale decir, no solo desafían al Estado mexicano en cuanto al monopolio de violencia se refiere, sino también usurpan funciones como recaudación de impuestos mediante el cobro de cuotas. En efecto, se estima que Los Templarios obligaban a la mayoría de las 113 alcaldías michoacanas a entregarles 10\% del dinero que reciben del Gobierno Federal (Ernst, 2014).

Asimismo, para alcanzar sus objetivos pueden perseguir algunos fines políticos, buscando tener en un contexto de estabilidad formas de influencia que les permitan impunidad para desarrollar sus ilícitos. Por ejemplo, las elecciones municipales de 2011 pusieron de manifiesto el nivel de influencia que ejerce este grupo criminal sobre las decisiones de los habitantes y autoridades locales en Michoacán. En efecto 
[c] omo en ninguna otra entidad, se registraron varios incidentes que apuntaban hacia una intervención activa del cartel en el proceso electoral, [pero sólo con el propósito utilitarista de asegurar que fuera electo un candidato funcional a sus intereses económicos]. Por una parte, se difundieron grabaciones en las que se mencionaba que Los Caballeros Templarios contribuyeron con dos millones de dólares a la campaña del candidato de izquierda. Sin embargo, de acuerdo con la candidata del Partido Acción Nacional, María Luisa Cocoa Calderón, el candidato del [Partido Revolucionario Institucional] —Fausto Vallejo, quien resultó ganador- fue quien más se vio favorecido por la cúpula del cartel. Entre las irregularidades que la candidata señaló destacan la intimidación a actividades proselitistas (incluyendo la irrupción de un comando armado en su casa de campaña); bloqueos carreteros para dificultar el acceso a casillas y negación de voto a ciertas personas que no contaban con "autorización". (Guerrero, 2014)

De tal suerte que su irrupción en la escena criminal representa el momento culmine de la pax mafiosa: ser más eficaz y confiable que la propia autoridad. En otras palabras, Los Caballeros Templarios han dado un salto cualitativo en la trayectoria reciente del crimen organizado azteca, penetrando distintas comunidades vulnerables

por medio de empleos, seguridad pública, ayuda a los pobres, rehabilitación de alcohol y drogas, vinculación con las mejores familias, entre otros, convirtieron a este grupo criminal en el arquetipo de una nueva realidad en México en donde ya no únicamente era narcotráfico y el crimen en todas sus modalidades, sino una verdadera afrenta al Estado. (Bolaños Vázquez, 2015, p. 30)

Como se mencionó previamente, al igual que Los Zetas, los miembros de este singular cartel realizan una captura expoliadora de su ambiente que va más allá de la extracción de rentas, llegando a controlar la autoridad, gobiernos locales y sociedad. Configurando así la expresión más penetrante y compleja que haya alcanzado nunca el crimen organizado en suelo azteca (Aguilar Camín, 2015).

Sin duda la insurrección y criminalidad organizada son métodos organizativos que se oponen en algún ámbito al Estado, lo que se traduce en pautas para no ser desarticulados por los poderes públicos y mantenerse en la clandestinidad. Pero su naturaleza es distinta y se establece según qué fin persigan; el rebelde en la mayoría de las ocasiones desafía y busca un cambio en su política, mientras el narcotráfico puede convivir con el Estado y no exigirle nada, eludir el choque y vivir en paralelo. En ocasiones, el crimen organizado se enfrenta al Estado para que se abstenga de reprimir una serie de actividades, controlar 
rutas para los tráficos ilícitos o impartir justicia, es decir, para cuestionar el monopolio de la violencia. Pero en la insurgencia donde también se da ese cuestionamiento de la violencia estatal, la violencia es inherente, ya que toda insurrección opone un proyecto ideológico al Estado, lo cual supone un componente subversivo del que carece un cartel como Los Caballeros Templarios (Pérez Caballero, 2015, pp. 155-156).

Utilizar una estrategia o táctica similar al insurrecto no modifica los propósitos u objetivos de Los Templarios, ya que se trata de un actor criminal carente de demandas hacia el Estado o agravios históricos que impulsen su accionar. Por consiguiente, dado que el ánimo de lucro es un elemento sine qua non del narcotráfico, puede sostenerse que el crimen organizado y la insurgencia son dos maneras de realizar determinadas actividades (la obtención de un beneficio económico y la violencia política), que poseen como elemento común la organización y lo que lleva aparejada su condición de entidades enfrentadas, con más o menos intensidad, al Estado. Precisamente esa graduación en cuanto al reto que cada uno representa establece una clara distinción entre ambos actores armados no estatales.

\subsection{Apoyo popular}

En segundo lugar, las organizaciones criminales no cuentan con una representación simbólica como defensores del pueblo. Sin embargo, la insurgencia como el narcotráfico son fenómenos que al estar contra el Estado se comportan de forma parecida. Ambos aplican de forma instintiva los mismos principios para controlar el territorio y a quienes habitan en este. En efecto, el proceso de control territorial por parte de narcotraficantes y rebeldes se cimienta en rasgos símiles:

- Construir el mayor soporte social posible.

- $\quad$ Establecer un dominio de inteligencia superior al Estado.

- Aumentar y desplegar poder armado de forma cada vez más abierta.

- Cooptar, someter, sustituir o expulsar a la autoridad local.

- Ejercer plena autoridad sobre el territorio y población. 
El centro de gravedad de las bandas criminales, al igual que muchas insurgencias, es el apoyo popular. No obstante, existe una diferencia moral entre ellos, dado que el respaldo social es un elemento clave de la insurrección y ocupa una posición central en su estrategia. El reconocimiento y aceptación por parte de la población local son fundamentales para el movimiento y determinarán en gran medida las probabilidades de su éxito o fracaso. Percepción que es reforzada por RACBI: "Una lucha entre la insurgencia y el poder establecido es por la legitimidad, sobre quién y cómo debe gobernar. Uno de los elementos centrales es conseguir el respaldo social. Quien lo consiga, a la larga triunfará" (Sohr, 2015, p. 152).

De ese modo, los rebeldes buscan incrementar su legitimidad cultivando una percepción como protectores sociales, los grupos criminales no. Los insurrectos realizan una labor político-ideológica para lograr apoyo, mientras los carteles emplean más la economía criminal e intimidación. O sea, los subversivos instrumentan el descontento social y los narcos la codicia individual, debido a que el tráfico de drogas es más rentable y tiene menores costos de transacción, las poblaciones locales con frecuencia optan por participar en economías ilícitas. Por ende, el involucramiento de la comunidad permite a grupos criminales obtener una importante cuota de capital político, cuya extensión les facilita el dominio de inteligencia; una vez logrado esto, les es más factible evadir las fuerzas de seguridad en un primer momento y luego optar por cooptarlas o atacarlas.

Cada vez más, los carteles se han involucrado activamente en la prestación de servicios públicos en las comunidades donde operan, como un proto-Estado, ocultándose bajo el manto de "bandidos sociales" (Sullivan y Elkus, 2010). No menos cierto es, con todo, que, en contraste con los sistemas extensivos y altamente formalizados de prestación de servicios de algunas insurrecciones, la prestación de servicios por carteles mexicanos es relativamente menos frecuente, menos visible y más cortoplacista. De hecho, la mayoría de los servicios prestados por ellos son en gran medida con fines de propaganda o relaciones públicas, no muy diferente de las actividades caritativas realizadas por empresas y corporaciones.

Como sugiere Flanigan (2014), existe una relación entre la prestación de servicios por grupos criminales y el apoyo de los receptores. De manera tal que los carteles emplean la prestación de servicios como una herramienta eficaz para generar apoyo o disminuir la resistencia en la comunidad hacia las actividades que desarrollan, pues cabe señalar que la población local no necesariamente las acepta genuinamente.

172 Si Somos Americanos. Revista de Estudios Transfronterizos 
Como se aprecia en la figura 1, el grado en que una comunidad tolera a las organizaciones narcotraficantes es variable, se extiende a través de una amplia gama que va desde un completo rechazo y resistencia activa; a la aceptación pasiva debido al silenciamiento sutil o la coacción; hasta la aceptación genuina dada la opinión favorable generalizada de la población local; con la participación activa de la comunidad en economías ilícitas. De ese modo, los carteles pueden utilizar la prestación de servicios como una herramienta para movilizar a la comunidad a lo largo del espectro de aceptación. Particularmente, los servicios sociales y otros beneficios económicos ofrecidos pueden servir para mover a la población hacia la derecha de este continuo.

Figura 1: Continuum tolerancia población local frente a crimen organizado

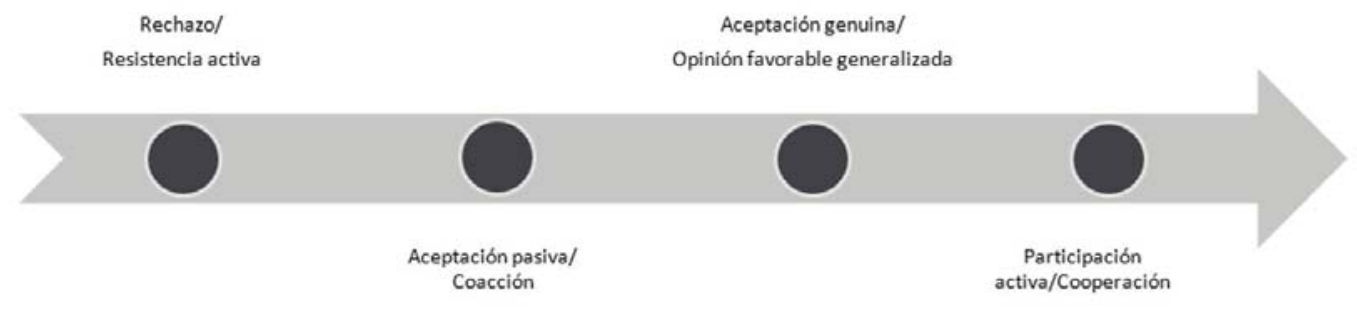

Fuente: Elaboración propia a partir de Flanigan, 2014.

La prestación de servicios puede ser una herramienta útil en este sentido, debido a la dinámica de poder que existe en la configuración del servicio. La relación entre proveedores de servicios y destinatarios se rige por el poder que cada uno puede aportar al intercambio. La cuota de poder que un proveedor de servicios tiene sobre el destinatario guarda directa relación con la capacidad del receptor para obtener la ayuda deseada. El destinatario del servicio, en este caso la comunidad local, a menudo no está en condiciones de elegir a los proveedores, ni de rechazar aquellos servicios que satisfagan sus necesidades básicas de alimentación, salud, vivienda o educación.

Desde esa perspectiva, resulta de suma utilidad incorporar a nuestro análisis la tesis planteada por Romero y Díaz-Cayeros (2014), quienes sostienen que el patrón de interacción de organizaciones narcotraficantes con las comunidades se encuentra sujeto a dos posibles factores: el grado de control territorial y la captura del Estado. En situaciones de absoluto dominio territorial, los carteles tienen más posibilidades de cosechar las ganancias derivadas de la moderación en el futuro e incluso pueden proporcionar ciertos beneficios a la comunidad. Tratan de ganarse las mentes y corazones de los residentes no por razones benévolas, sino para prevenir que otros carteles conquisten su área. 
Otra posibilidad es que los carteles con mayor arraigo en sus comunidades mediante su integración al proceso productivo pueden ser menos propensos a abusar, ya que requieren la cooperación continua de los habitantes para sostener su economía ilícita.

Así, el nivel de colaboración de la población civil con el crimen organizado constituye un determinante crucial de la fortaleza estatal, pero también un indicador de la capacidad de un cartel para competir con el gobierno por la lealtad de sus habitantes. Sin embargo, cabe resaltar que la proporción de beneficios por actores armados no estatales es compleja y no puede caracterizarse únicamente por las implicaciones negativas para la ciudadanía. Esto debido a que la prestación de servicios por parte de grupos criminales no siempre es señal de ausencia de autoridad formal, pudiéndose llevar a cabo en complicidad o cooperación con el gobierno. Por ejemplo, Arias (2006) describe las redes existentes entre facções criminosas, dirigentes sociales, funcionarios públicos y policías en las favelas de Río de Janeiro, que sirven para entrelazar el sistema socioeconómico y político con los residentes.

Como apunta Corcoran(2013), en sus "más de 53 mandatos, el manifiesto de Los Templarios evoca una imagen como una banda de Robin Hood que luchan desinteresadamente por la liberación y prosperidad de Michoacán”. En efecto, este grupo criminal se presentó formalmente en marzo de 2011 en Michoacán, declarando que continuaría con "las actividades altruistas que antes realizaba La Familia Michoacana" (Bolaños Vázquez, 2015, p. 28). Incluso, distribuyó en bares y tiendas de su ciudad natal el llamado Código de Los Caballeros Templarios de Michoacán, un cuadernillo cuyo contenido emula las reglas de disciplina y honor del Medioevo. Así, en sus páginas se lee: "Donde hay debilidad allí el templario debe llevar su fuerza. Donde no hay voz allí el templario debe llevar la suya. Donde están los más pobres allí el templario debe distribuir su generosidad" (Bartolomé, 2011, p. 139).

Otro mandamiento proclama que la misión más importante del cartel es la protección de las personas y territorio michoacano. Es más, durante una amplia entrevista que fue subida a YouTube, Servando La Tuta Gómez, exprofesor y líder de Los Caballeros, declaró:

Hacemos muchas cosas ilícitas, pero hay cosas que se pueden hacer y cosas que no se pueden hacer[... ] No podemos meternos con la ciudadanía, ni la gente de trabajo, a la gente que se dedica a trabajar y a producir legalmente. [...] Nosotros creemos, y tenemos el concepto claro, de que somos servidores. [...] Nosotros queremos que haya trabajo, que haya educación y que haya salud. (Althaus, 2013)

174 Si Somos Americanos. Revista de Estudios Transfronterizos 
Por último, el escrito realiza un llamado a la sociedad michoacana para que otorgue su comprensión y ayuda en su cruzada contra el crimen. De acuerdo con una investigación realizada por la revista Proceso, "el grupo dice financiarse con aportaciones voluntarias de empresarios, comerciantes y agricultores. Pero autoridades, organizaciones empresariales y campesinas han expresado que, en realidad, se trata de extorsiones que representan hasta un $80 \%$ de sus ingresos mensuales" (Nájar, 2013).

Pese a que muchos elementos podrían ser llamativos,

para las personas familiarizadas con Los Templarios, gran parte de su manifiesto es ridículamente hipócrita. Mientras se muestran a sí mismos como defensores de Michoacán, [autodenominándose movimiento social templario, en rechazo a su designación como cartel, el texto no dice nada sobre sus intereses económicos. Por ejemplo, aunque] prohíbe el secuestro, el manual omite la extorsión, una práctica notoria en Los Caballeros, que como el secuestro, suele tener como objetivo a la población local. (Corcoran, 2013)

En otras palabras, bajo esa fachada benevolente se oculta su real objetivo: la participación en mercados ilícitos y actividades delictivas mediante el uso indiscriminado de violencia, aunque el cartel conciba su accionar como una expresión de justicia divina.

La mixtura entre pensamiento y prácticas de carácter templario con tradición guerrillera otorgó a este grupo criminal un perfil muy especial en comparación a otros actores del hampa mexicano, pues ambas corrientes contienen un mensaje de liberación. En esa dirección, la extrema violencia ejercida por este cartel en su operación (tráfico, secuestro y extorsión) es legitimada por dos componentes narrativos: uno religioso de liberación personal encarnado por El Chayo y otro de izquierda montado en el argumento de defensa de la patria, articulado por La Tuta, ambos cabecillas de la organización.

Simultáneamente, fundamentan la solidez del movimiento estrechando sus lazos con la población local, es decir, la construcción de una base social que los defienda y en la cual fundirse y ocultarse de adversarios. A modo de ejemplo, cabe resaltar que en gran parte de su área de influencia, Los Caballeros Templarios gozan de un halo de protección social que los blinda de incursiones territoriales de enemigos como el Cartel de Jalisco Nueva Generación (CJNG). Por lo tanto, es posible sostener que Los Templarios construyen una figura similar a los Contras en Nicaragua; o sea, carteles rivales como CJNG, pasan a ser considerados no solo una amenaza para el propio grupo criminal, sino también para 
la comunidad michoacana. Requiriéndose, entonces, de un frente común en contra del agresor externo (Ernst, 2014).

Empero, si bien el lenguaje que ocupa es absolutamente condescendiente y deshonesto, el manual resulta de suma utilidad a efectos de ilustrar el concepto que tienen Los Caballeros de sí mismos. Dando cuenta que ellos se perciben como un grupo único y excepcional, con un propósito superior al de narcotraficantes comunes (Corcoran, 2013). De ese modo, Los Templarios inauguraron, sobre la base del modelo criminal instaurado por Los Zetas, un nuevo estilo delincuencial con una estrategia diferente cimentada en dos pilares:

- Utilizar un discurso novedoso en el cual dicen ser una organización producto de la misma sociedad para defenderla de grupos criminales fuereños que la oprimen.

- Enmascarar su naturaleza ilícita detrás de una supuesta base de apoyo social, construida mediante el reparto de algunos beneficios para reducir la resistencia y el descontento con relación a sus crímenes

La provisión de un grado mínimo de orden social o ley fáctica no se debe solo a una "vocación de servicio al prójimo", como aseguró El Chayo en algún momento, sino también y quizás primordialmente, a una lógica de generación de apoyo popular (Ernst, 2014). En ese sentido, cabe subrayar que su capacidad para distribuir bienes y servicios le permitió construir una sólida base social. Para obtenerlo, "el cartel puso en práctica una estrategia novedosa, pues además de contar con una amplia red de vínculos en la policía municipal, extendió su presencia en áreas de desarrollo social y obra pública de los ayuntamientos" (Guerrero, 2014).

Por ejemplo, las comunidades ven recompensada su colaboración con el grupo criminal a través de la construcción de un hospital, la pavimentación de una calle o el acceso a agua potable. En consecuencia, mediante este modus operandi, Los Templarios han podido desempeñarse como una autoridad más eficaz para satisfacer las demandas comunitarias que el propio gobierno municipal (Guerrero, 2014).

Y aunque su identificación con el entorno es considerable y en muchos sentidos han adquirido la condición de moverse como pez en el agua, siguiendo la metáfora utilizada por Mao Tse Tung, lo cierto es que Los Caballeros son ante todo una organización criminal. No se debe perder de vista que el crimen organizado no es un mundo tajantemente separado de sus sociedades anfitrionas. Más que burocracias autónomas y aisladas, los 
actores criminales funcionan como redes sociales que se entrelazan con las altas esferas de élites al igual que con esferas cotidianas de los ciudadanos de a pie. Los criminales más hábiles, al igual que los guerrilleros más exitosos, se mueven como peces en el agua entre la población civil (Schedler, 2013). Por ende, siguen el esquema de interacción clásico entre organización criminal, sociedad y Estado pues, hasta las organizaciones criminales más poderosas se enraízan en la sociedad, pudiendo coexistir en paralelo con el Estado y no alterarlo de manera material. Soslayándose aquí los aspectos morales pues, un estado de impunidad generalizado puede socavar a largo plazo la sociedad, y acabar por transformar el Estado.

\subsection{Uso de la violencia}

En tercer lugar, las organizaciones criminales no pueden ser definidas únicamente a partir de las acciones violentas que ejecutan o métodos agresivos que utilizan para responder a la ofensiva estatal o confrontar a sus rivales. Para efectos de distinguirlos, Schedler, en The Criminal Subversion of Mexican Democracy ofrece cuatro dimensiones fundamentales sobre la morfología de la violencia (ver tabla 4).

TABLA 4

Dimensiones fundamentales morfología de la violencia

\begin{tabular}{cl}
\hline Dimensión & Conceptualización \\
\hline $\begin{array}{c}\text { Destinatario final } \\
\text { (agentes estatales o } \\
\text { ciudadanos) }\end{array}$ & $\begin{array}{l}\text { Actores armados no estatales difieren en sus objetivos } \\
\text { primarios. Pueden dirigir sus actos violentos ya sea } \\
\text { contra agentes estatales o ciudadanos. }\end{array}$ \\
\hline $\begin{array}{l}\text { Grado de organización } \\
\text { (individual o colectiva) }\end{array}$ & $\begin{array}{l}\text { Ciudadanos violentos pueden actuar como lobos } \\
\text { solitarios, pertenecer a redes de cooperación } \\
\text { esporádicas o construir organizaciones complejas y } \\
\text { jerárquicas }\end{array}$ \\
\hline
\end{tabular}




\begin{tabular}{|c|c|}
\hline $\begin{array}{c}\text { Motivaciones } \\
\text { (políticas o comunes) }\end{array}$ & $\begin{array}{l}\text { Cuando los actos de violencia parecen estar motivados } \\
\text { por preocupaciones generales como las políticas } \\
\text { públicas, instituciones del Estado o composición de } \\
\text { la comunidad política, se habla de violencia política. } \\
\text { Cuando parecen estar motivados por intereses } \\
\text { particulares como la rentabilidad, se trata de violencia } \\
\text { criminal. }\end{array}$ \\
\hline $\begin{array}{c}\text { Relaciones de poder } \\
\text { (dominación, competencia y } \\
\text { rebelión) }\end{array}$ & $\begin{array}{l}\text { Particulares pueden recurrir a la violencia contra } \\
\text { adversarios más débiles que ellos, sirviendo como } \\
\text { herramienta de dominación. Cuando los grupos } \\
\text { sociales recurren a la violencia contra otros grupos de } \\
\text { nivel similar, sirve como instrumento de competencia. } \\
\text { Cuando actores de menor rango ejercen la violencia } \\
\text { contra miembros de mayor nivel jerárquico, se habla } \\
\text { de rebelión. }\end{array}$ \\
\hline
\end{tabular}

Fuente: Elaboración propia a partir de Schedler, 2014.

Cabe resaltar que la literatura especializada muchas veces tiende a obviar sus implicaciones morales. Varias ramas de las ciencias sociales, tales como criminología, economía o ciencia política, enfatizan la naturaleza racional de la violencia, su valor instrumental o utilitario. Se le imputan ciertos fines y medios (Schedler, 2014). Desde ese ángulo, "cuando se habla de insurgencia, no se hace referencia al ejercicio de un tipo de violencia fortuita, aleatoria o sin orden, sino a una violencia que persigue un objetivo concreto de naturaleza política" (Guindo, 2013, p. 289). Incluso, los insurrectos como actores políticos utilizan la violencia por cinco razones: deserción, intimidación, provocar una respuesta gubernamental, estropear las negociaciones, y como la publicidad para su causa (Phillips, 2015).

En cambio, este tipo de violencia es incoherente con los objetivos perseguidos por asociaciones ilícitas como los carteles, pues esta constituye una herramienta. O sea, los grupos criminales, sin recursos legales, la utilizan para hacer valer acuerdos, pero su empleo excesivo suele ser costoso, ya que puede resultar en la muerte o encarcelamiento de los autores. Como es posible inferir, su objetivo es totalmente diferente al aludido por grupos insurgentes en tanto busca proteger o expandir territorialmente actividades ilegales. En consecuencia, la insurgencia se distingue de otras formas de violencia al estar

178 Si Somos Americanos. Revista de Estudios Transfronterizos 
impulsada por la injusticia moral (queja formal), a diferencia de los actos criminales que tienen intereses personales (codicia).

En este sentido, Lessing argumenta que la violencia ejercida por los carteles obedece a un lobby violento: "Lo que están haciendo es decirles a los funcionarios públicos o rivales: Hablo en serio, puedo causarte muchísimo dolor. Así que más te vale hacer lo que digo" (Grillo, 2015). De ese modo, la violencia asociada al narcotráfico también puede tener un fin intimidatorio, o bien entrar en una espiral de crímenes con el objetivo de causar temor en la población. Este fenómeno es conocido como narcoterrorismo. Haupt (2009) distingue dos modalidades de narcoterrorismo: el cometido por narcotraficantes con diversos fines; o bien, el involucramiento de organizaciones terroristas en el narcotráfico para financiar su causa y operaciones contra el Gobierno. En el caso de México, el narcoterrorismo es perpetrado por Los Templarios, cubriendo todo el espectro de objetivos, a saber:

- Organizaciones narcotraficantes rivales.

- $\quad$ Fuerzas de seguridad (policías y militares).

- $\quad$ Autoridades gubernamentales.

- Población civil.

Un ejemplo que suele utilizarse para ilustrar esta conceptualización es un ataque incendiario perpetrado por Los Caballeros Templarios en mayo de 2012 contra cuarenta vehículos repartidores y cinco bodegas de la compañía transnacional Sabritas (filial de PepsiCo), situada en las poblaciones de Apatzingán, Lázaro Cárdenas y Uruapan, en Michoacán, así como en Salvatierra y Celaya, Guanajuato, en un aparente acto de extorsión (Looft, 2012). Sin embargo, dos días con posterioridad a la agresión, aparecieron una decena de narcomantas ${ }^{2}$ en algunas calles céntricas de Apatzingán con mensajes en los que el grupo criminal se atribuía la autoría del ataque a las instalaciones de la mencionada empresa, aduciendo que sus camiones eran utilizados para trasladar agentes encubiertos hacia áreas bajo su dominio, agregando que se trataban de

2 Las narcomantas pueden considerarse un esfuerzo publicitario de los mismos carteles que las colocan en espacios públicos — por ejemplo, en pasos peatonales_ con la finalidad de atraer la atención de la sociedad civil y de los medios para que las reproduzcan y divulguen, y por esta vía generar una articulación alternativa a las comunicaciones de los actores gubernamentales. Ver Maihold (2011, p. 84). 
actividades nocivas para nuestra hermandad [...] reconocemos que las empresas son fuentes de empleo para el pueblo michoacano y respetamos su labor. Por ello, llamamos a los empresarios a limitarse exclusivamente al ámbito de sus negocios, o de lo contrario serán castigados. (Martínez, 2012)

No obstante, es necesario destacar que el narcoterrorismo en tanto categoría analítica carece de valor explicativo, pues la intersección de ambos términos (narcotráfico y terrorismo), imprecisa desde el punto de vista teórico, genera distorsiones conceptuales, dificultando la adecuada comprensión de la violencia ejercida por este cartel. En la Guerra contra el narcotráfico fue apareciendo una nueva víctima: la población civil; el uso de la violencia se dirigió progresivamente hacia ese segmento producto de la escalada del conflicto y un nuevo tipo de vínculo establecido por el crimen organizado en sus dos variantes, narcotráfico y extractores de rentas sociales (Valdés, 2013). Lo cierto es que la violencia provocada por dinámicas propias de la criminalidad organizada no puede confundirse con aquella perpetrada por organizaciones terroristas, pues el atentado cometido por Los Templarios constituye un caso excepcional o anómalo, no un precursor en tanto representa una expresión de control territorial, lo cual no requiere ser redefinido bajo conceptualizaciones como Insurgencia Criminal.

Igualmente, conviene puntualizar que el terrorismo no es una forma de guerra, sino una táctica que puede ser empleada de modo combinado con una serie de pasos en la escala de la guerra en su conjunto. Como se indicó anteriormente, en México existen algunos actores armados no estatales que se caracterizan por exhibir ciertos rasgos de protoinsurgencia, tendiendo a utilizar tácticas terroristas que generan alarma social, como Los Templarios. Característica que puede hacerlos parecer, ante una visión hiperideologizada como la prevaleciente en distintos círculos de poder en Estados Unidos como una insurrección (Fernández, 2011). Empero, esta organización criminal se aproxima más bien a lo que se denomina Oponente Híbrido, pues simultánea y adaptativamente fusiona la utilización de armas convencionales, tácticas irregulares, terrorismo y comportamiento criminal en el espacio de batalla (Hoffman, 2012). De hecho, su caso es similar a otros grupos delictivos operativos en la región como Los Urabeños ${ }^{3}$ o Comando Vermelho ${ }^{4}$.

3 Los Urabeños, también conocidos como Autodefensas Gaitanistas de Colombia, son una de las organizaciones narcotraficantes más ambiciosas y despiadadas de Colombia. Es una de las varias bandas criminales conformadas por ex mandos medios paramilitares que se han caracterizado por su extrema violencia. Ver Charles y Bargent (2017).

4 El Comando Vermelho es la facción criminal más longeva de Brasil, nació en la cárcel Cándido Méndes, ubicada en Río de Janeiro, durante la década de 1970 como un grupo de autoprotección para los reclusos. En sus inicios, se involucró en actividades criminales menores como robos de bancos, pero en la década de 1980 mutó hacia 


\subsection{Sujetos de mediación}

En cuarto lugar, los insurgentes como actores armados no estatales movilizados por agendas u objetivos políticos son, en principio, interlocutores válidos susceptibles a estrategias de mediación, trato que resulta inaplicable a organizaciones involucradas en actividades criminales (Plant y Dudouet, 2015). No debe perderse de vista que los grupos criminales están motivados principalmente por ánimo de lucro, mientras que los rebeldes por lo general buscan acceder al poder estatal o cambiar el orden establecido. Siendo difícil aceptar la existencia de grupos criminales que deseen el poder político, excepto para corromperlo, comprarlo y realizar exitosamente sus negocios.

Para Cockayne (2013), la mediación con actores criminales ha sido históricamente común, y puede ser un aspecto cada vez más común del arte de gobernar una economía transnacionalizada. Dicho postulado se encuentra imbuido en una visión pragmática, pues implica la convivencia del Estado con un cierto grado tolerado de actividad ilícita cuyo objetivo es reducir o cesar la violencia mediante un acuerdo entre las organizaciones criminales por una parte, y la autoridad del Estado legitimada u otros actores habilitados para la mediación, por la otra, de forma análoga al papel que el Derecho Internacional Humanitario desempeña entre actores armados convencionales. En efecto, esta opción representa una oportunidad para expresar demandas racionales y promover cierto grado de compromiso por parte de los involucrados, aun cuando las conversaciones no deriven necesariamente en la finalización del conflicto.

No obstante, al optar por esta línea de acción se deja en evidencia la debilidad estatal, pues conduce a analizar el problema desde la lógica de los criminales, en vez de revisar y fortalecer las capacidades institucionales. O sea, esta tesis se opone a confrontar al crimen organizado e intenta encontrar caminos para pacificar a los criminales, en vez de fortalecer al Estado para controlarlos. Lo primero luce más confortable que lo segundo, toda vez que depende de los criminales, mientras que lo segundo requiere un gran esfuerzo propio. Por ende, esta alternativa demuestra que a menudo se utiliza la aplicación de la ley de modo estratégico a objeto de estimular, tolerar o simplemente administrar la violencia, en vez de reprimirla. Siendo posible observar que a un gobierno no siempre le interesa ejercer el monopolio de la violencia según los cánones weberianos.

el narcotráfico, trabajando en conjunto con carteles colombianos y asumiendo un rol de "autoridad" en varias favelas cariocas. Ver Insight Crime (2017). 
Un reporte elaborado por la Organización de Estados Americanos, titulado Searching for Common Approaches to Deal with Unconventional Conflicts and Violence in the Americas, indica que el diálogo es aceptado y alentado en conflictos armados convencionales, pero a menudo es difícil o desincentivado en lo que bajo Derecho Internacional Humanitario se conoce como Otras Situaciones de Violencia (OAS, 2015). Bajo esa lógica, Hope (2012) sostiene que las tratativas con grupos criminales son moral y políticamente muy complejas, en contraste con la ruta relativamente familiar de las negociaciones políticas, debido a que implica ceder en un principio básico como la no negociabilidad de la ley, transgrediéndose la ética de la convicción en sentido weberiano. De hecho, existen riesgos aún mayores cuando se trata de mediaciones en contextos no-bélicos, pues las organizaciones criminales pueden percibir que, si se vuelven suficientemente violentas, podrán sentarse a negociar con el gobierno con miras a recibir mayores concesiones.

Este dilema es ilustrado por la controversial tregua pactada entre la mara Salvatrucha (MS-13) y Barrio 18 en El Salvador durante 2012, que condujo a una reducción masiva y sostenida de los homicidios. El otrora presidente Mauricio Funes (2009-2014) inicialmente negó cualquier implicación, llegando a desestimar el impacto de la tregua en reducción de la violencia, pues significaba, en esencia, un reconocimiento tácito de que había dado su brazo a torcer ante las pandillas (Yagoub, 2014). Vale decir, se enviaba el siguiente mensaje: el Estado es débil y puede ser chantajeado.

Sin embargo, más tarde admitió públicamente su participación, atribuyéndose el crédito e invitando a los países vecinos a estudiar la política. Incluso,

por primera vez desde la guerra civil, se invitó a una misión del Comité Internacional de la Cruz Roja a monitorear la situación [...], la [Organización de Estados Americanos] dio un paso arriesgado al apoyar de forma abierta el proceso y, cuando el Gobierno reconoció su propio apoyo, la [Unión Europea] también participó [en las conversaciones]. (González Bustelo, 2016)

Cuatro años más tarde, el nuevo presidente Salvador Sánchez Cerén (2014-2019) no solo rechazó la tregua por considerarla éticamente sospechosa y estratégicamente equivocada, sino que puso en marcha una represión cada vez más militarizada contra las maras. De hecho, recientemente se aprobó una ley que prohíbe la negociación con ellas, e incluso penaliza los "llamados al diálogo" (Tabory, 2016).

Desde esa óptica, Farah (2012) argumenta que en el caso salvadoreño la pacificación negociada representó una apuesta política alta, pues “al ofrecerle a los líderes pandilleros

182 Si Somos Americanos. Revista de Estudios Transfronterizos 
encarcelados mejores condiciones de reclusión a cambio del cese a las ejecuciones, extorsiones y el reclutamiento infantil, la administración Funes corría el riesgo de empeorar la situación de seguridad pública a largo plazo" (p. 1).

Según el autor, la tregua permitió a las maras reorganizarse, rearmarse y empoderarse, al otorgarles una cuota de poder político, la cual radicó en el mejoramiento de los indicadores de seguridad registrados durante ese período. Fue así como en los primeros cien días posteriores a la entrada en vigencia de la cesación, el promedio de homicidios diarios en El Salvador cayó de catorce a cinco (Ramsey, 2012).

No obstante, cabe señalar que la tregua de maras logró bajar los homicidios porque las pandillas se dividieron los territorios bajo intermediación de terceros con anuencia del Estado, con ello ya no necesitaron matarse. Vale decir, los mareros podían forzar un colapso en cualquier momento simplemente amenazando con incrementar el número de homicidios. Incluso, los cabecillas "sorprendidos y satisfechos con los resultados de las negociaciones, empezaron a entender que el control territorial y la cohesión hacen posible que expriman concesiones del Estado, mientras mantienen la esencia criminal de su carácter" (Ramsey, 2012).

En resumen, la polarización social en torno a la delincuencia organizada y la instrumentalización de este asunto como una herramienta electoral tiene profundas consecuencias sobre la posibilidad de optar por la mediación con grupos criminales para disminuir los índices de violencia y criminalidad a escala nacional. No obstante, para los partidarios de un enfoque más represivo, estas medidas seguramente parecerán ingenuas o poco éticas. Las políticas de distensión son siempre políticamente difíciles de asimilar, y más aún cuando la contraparte es un grupo criminal con ninguna ambición políticoideológica. Los gobiernos temen una reacción adversa de la opinión pública y una cobertura mediática negativa sobre la iniciativa, así como un alto precio a pagar en réditos político-electorales (Garrigues, 2015). Como resultado, su apoyo a las conversaciones suele ser discontinuo o volátil, y sus definiciones públicas más bien contradictorias, pues en un comienzo niegan rotundamente su participación, pero a medida que avanzan reconocen abiertamente su injerencia.

A partir de lo anterior, es posible deducir que si el Gobierno mexicano iniciara una tregua sin un plan para fortalecerse, Los Caballeros acumularían fuerzas mediante el potenciamiento de su organización, reclutamiento, control territorial y fuentes de financiamiento. De ese modo, el concepto Insurgencia Criminal presenta el inconveniente de otorgarles legitimidad beligerante injustificada a actores criminales 
como Los Templarios, en la medida que potencialmente estos serán considerados como interlocutores válidos frente al Gobierno, lo cual supondría tener la capacidad de firmar un cese al fuego, elemento crucial para reducir el impacto sobre la población civil (Hellestveit, 2015). Convirtiéndolos así en poderes fácticos, condición que autorizaría a funcionarios y agentes del sector de seguridad y justicia a colaborar con ellos por temor o por dinero. Además, significaría malinterpretar su verdadera naturaleza, avalando la aplicación de un régimen jurídico como el Derecho Internacional de los Conflictos Armados, lo que podría desencadenar una escalada de violencia estatal inadecuada para responder al desafío planteado por este cartel.

Empero, la posibilidad de que líderes e integrantes de este singular grupo criminal estén dispuestos a renunciar al uso de mecanismos de intimidación no suma muchos adeptos. Ante todo predomina la postura (no menos fundada) de que la dignidad humana es la última de las prioridades para Los Caballeros. Más aún, la herramienta que esta organización criminal utiliza para establecer su presencia, dominio y administrar sus actividades ilícitas en Michoacán consiste precisamente en quebrantar la dignidad humana. En consecuencia, no queda claro si están en posición de firmar acuerdos, entregar armas o cuál sería el estado final deseado en el caso hipotético de que existiera voluntad de dialogar con ellos.

\section{Conclusiones}

A partir de lo expuesto con anterioridad, se desprende que la reinterpretación del actuar de Los Templarios bajo la modalidad de Insurgencia Criminal enfatiza únicamente la utilización de tácticas y estrategias conforme a su definición clásica, junto a su efecto más nítido: debilitamiento o impedimento del ejercicio pleno de las funciones estatales, en especial, el control efectivo sobre la totalidad del territorio nacional. No obstante, ignora $\mathrm{u}$ omite por completo la verdadera naturaleza de las metas de quienes protagonizan los movimientos insurreccionales.

Si bien el modus operandi de este grupo criminal a menudo se asemeja a la insurgencia porque se opone armadamente a la autoridad dentro de un determinado territorio y goza de cierto apoyo social, lo cierto es que en muchos casos su causa no está inspirada tanto en agravios reales o imaginarios, como en codicia y depredación de bienes públicos y privados. De ese modo, esta nueva lectura puede resultar ilustrativa para hablar de saltos cualitativos en relación con las estrategias implementadas por algunos carteles

184 Si Somos Americanos. Revista de Estudios Transfronterizos 
como Los Templarios, pero tiende a mantener cada uno de los componentes del término (insurgencia y criminal) en la ambigüedad teórico-conceptual, fomentando una interpretación tergiversada e ideologizada del fenómeno.

En cuanto a sus implicancias políticas asociadas a la Guerra contra el narcotráfico, vale subrayar que el concepto Insurgencia Criminal presenta el inconveniente de otorgarles legitimidad beligerante injustificada a actores criminales como Los Templarios, en la medida que potencialmente estos serán considerados como interlocutores válidos frente al Gobierno, lo cual supondría tener la capacidad de firmar un cese al fuego, elemento crucial para reducir el impacto sobre civiles. Convirtiéndolos así en poderes fácticos, condición que autorizaría a funcionarios y agentes del sector seguridad y justicia a colaborar con ellos por temor o por dinero. Además, significaría malinterpretar su verdadera naturaleza, avalando la aplicación de un régimen jurídico como el Derecho Internacional de los Conflictos Armados, lo que podría desencadenar una escalada de violencia estatal inadecuada para responder al desafío planteado por este cartel.

Finalmente, es oportuno mencionar que al extender el concepto de insurgencia a campos ajenos para incluir a todas las expresiones criminales motivadas por un interés económico con el fin de corromper, neutralizar o defenderse de los agentes encargados de aplicar la ley, se genera un vaciamiento de contenido. De manera tal que el término pierde prácticamente su significado original en razón de que esta nueva categoría englobaría fenómenos tan heterogéneos como Los Caballeros Templarios, Fuerzas Armadas Revolucionarias de Colombia, Sendero Luminoso, Los Urabeños o Comando Vermelho.

\section{Referencias}

Aguilar Camín, H. (1 de enero de 2015). La captura criminal del Estado. Nexos. Recuperado de http://www.nexos.com.mx/?p=23798

Althaus, D. (13 de agosto de 2013). ¿Son los Caballeros Templarios el tercer cartel más poderoso de México? Insight Crime Crimen Organizado en las Américas. Recuperado de http://es.insightcrime.org/analisis/son-caballeros-templarios-tercer-cartel-maspoderoso-mexico

Arias, D. (2006). The Dynamics of Criminal Governance: Networks and Social Order in Rio de Janeiro. Journal of Latin American Studies, 38(2), 293-325. 
Arratia, E. (2015). ¿Éxito táctico o fracaso estratégico? High Value Target y su aplicación a la guerra contra el narcotráfico (2006-2012). Si Somos Americanos, 15(2), 173-206.

Bartolomé, M. (2011). El creciente protagonismo de la desconocida segunda línea de organizaciones criminales mexicanas. Estudios Internacionales, 44(170), 135-139.

Baylis, J., Wirtz, J. y Gray, C. (2015). Strategy in the Contemporary World: An Introduction to Strategic Studies (5ta ed.). Oxford: Oxford University Press.

Bolaños Vázquez, C. (2015). Las experiencias de México durante la guerra contra el narcotráfico 2006-2012. URVIO-Revista Latinoamericana de Estudios de Seguridad, (15), 27-40.

Bunker, R. (2013). Introduction: the Mexican cartels-organized crime vs. criminal insurgency. Trends in Organized Crime, 16(2), 129-137.

Bunker, R. (2014). Fighting Irregular Fighters: Defeating Violent Non-state Actors. Parameters, $4(43), 57-62$.

Bunker, R. y Sullivan, J. (2010). Cartel evolution revisited: Third phase cartel potentials and alternative futures in Mexico. Small Wars \& Insurgencies, 21(1), 11-12.

Cardash, S. y Cilluffo, F. (2008). Mexico and the Triple Threat. En Cilluffo, F. y Tussing, B. (Eds.). The Hybrid Threat: Crime, Terrorism and Insurgency in Mexico ( $1^{\text {a }}$ ed., pp. 11-20). Washington, DC: U.S Army War College-George Washington University Homeland Security Policy Institute (HSPI).

Carroll, R. (9 de septiembre de 2010). Hillary Clinton: Mexican drugs war is Colombia-style insurgency. The Guardian. Recuperado de https://www.theguardian.com/world/2010/ sep/09/hillary-clinton-mexican-drug-war-insurgency

Cawley, M. (29 de octubre de 2013). Ataques a plantas de energía: ¿Una señal de la "narcoinsurgencia" en México? Insight Crime Crimen Organizado en las Américas. Recuperado de http://es.insightcrime.org/noticias-del-dia/ataques-a-plantas-deenergia-una-senal-de-la-narcoinsurgencia-en-mexico

Charles, M. y Bargent, J. (13 de julio de 2017). Inside Colombia’s BACRIM: Power. Insight Crime Crimen Organizado en las Américas. Recuperado de http://www.insightcrime. org/investigations/inside-the-bacrim-power

186 Si Somos Americanos. Revista de Estudios Transfronterizos 
Cockayne, J. (2013). Strengthening mediation to deal with criminal agendas. Geneva: Centre for Humanitarian Dialogue.

CONEVAL. (5 de febrero de 2015). Michoacán Pobreza 2014. Consejo Nacional de Evaluación de la Política de Desarrollo Social (CONEVAL). Recuperado de http://www.coneval. org.mx/coordinacion/entidades/Michoacan/Paginas/pobreza-2014.aspx

Corcoran, P. (17 de diciembre de 2013). Revelaciones del manual de adoctrinamiento de Los Caballeros Templarios. Insight Crime Crimen Organizado en las Américas. Recuperado de http://es.insightcrime.org/analisis/revelaciones-del-manual-de-adoctrinamientode-los-caballeros-templarios-de-mexico

DCAF. (2012). Armed Non-State Actors: Current Trends \& Future Challenges. Geneva: Geneva Centre for the Democratic Control of Armed Forces (DCAF).

Ernst, F. (1 de septiembre de 2014). En territorio templario. Nexos. Recuperado de http:// www.nexos.com.mx/?p=15463

Felbab-Brown, V. (2013). Crime-War Battlefields. Survival, 55(3), 147-166.

Fernández, J. (10 de febrero de 2011). EU y la narcoinsurgencia en México. Excelsior. Recuperado de http://www.excelsior.com.mx/node/712904

Finnegan, W. (31 de mayo de 2010). Silver or Lead: The drug cartel La Familia gives local officials a choice: Take a bribe or a bullet. New Yorker. Recuperado de http://www. newyorker.com/magazine/2010/05/31/silver-or-lead

Flanigan, S. (2014). Motivations and implications of community service provision by La Familia Michoacana/Knights Templar and other Mexican Drug Cartels. Journal of Strategic Security, 7(3), 63-83.

Garrigues, J. (2015). The case for contact: overcoming the challenges and dilemmas of official and non-official mediation with armed groups. ( $1^{\mathrm{a}} \mathrm{ed}$.). Oslo: Norwegian Peacebuilding Resource Centre (NOREF).

González Bustelo, M. (14 de marzo de 2016). ¿Es posible la mediación con grupos criminales? Blogs El País-Paz, en construcción. Recuperado de http://blogs.elpais.com/paz-enconstruccion/2016/03/es-posible-la-mediaci\%C3\%B3n-con-grupos-criminales-.html 
Grillo, I. (10 de julio de 2015). El terrorismo en la narcoguerra. Letras Libres. Recuperado de http://www.letraslibres.com/mexico-espana/el-terrorismo-en-la-narcoguerra

Grillo, I. (2012). El Narco Inside Mexico’s Criminal Insurgency. (1ª ed.). New York: Bloomsbury Press.

Grillo, I. (2016). Gangster Warlords: Drug Dollars, Killing Fields, and the New Politics of Latin America. ( $1^{\text {a }}$ ed.). London: Bloomsbury Press.

Guerrero, E. (1 de abril de 2014). La dictadura criminal. Nexos. Recuperado de http://www. nexos.com.mx/?p=20026

Guindo, M. (2013). Insurgencia y Contrainsurgencia. En Jordán, J. (Ed.). Manual de Estudios Estratégicos y Seguridad Internacional (1 ${ }^{\text {a }}$ ed., pp. 287-305). Madrid: Plaza y Valdés.

Haupt, D. (2009). Narco-Terrorism: An Increasing Threat to U.S. National Security. (1 $1^{\text {a }}$ ed.). Norfolk: Joint Forces Staff College.

Hellestveit, C. (2015). Tribes, thugs, terrorists and the law: can non-conventional armed violence be regulated? Oslo: Norwegian Peacebuilding Resource Centre (NOREF).

Hoffman, F. (2012). Future Hybrid Threats: An Update. (1 ${ }^{\text {a }}$ ed.). Washington, DC: Institute for National Strategic Studies.

Hope, A. (4 de junio de 2012). Pactar con delincuentes: Q\&A. Animal Político. Recuperado de http://www.animalpolitico.com/blogueros-plata-o-plomo/2012/06/04/pactar-condelincuentes-qa/

Insight Crime. (27 de febrero de 2017). Comando Vermelho. Insight Crime Crimen Organizado en las Américas. Recuperado de http://es.insightcrime.org/noticias-sobre-crimenorganizado-en-brasil/comando-vermelho-perfil

Jordán, J. (2012). Delimitación teórica de la insurgencia: concepto, fines y medios. En Baques, J. Jordán J. y Pozo, P. (Eds.). La seguridad más allá del Estado. Actores no estatales y seguridad internacional. (1 ${ }^{a}$ ed., pp. 113-134). Madrid: Plaza y Valdés.

Killebrew, R. y Bernal, J. (2010). Guerras del Crimen: Pandillas, Carteles y la Seguridad Nacional Estadounidense. (1 ${ }^{\mathrm{a}}$ ed.). Washington, DC: Center for a New American Security (CNAS).

188 Si Somos Americanos. Revista de Estudios Transfronterizos 
Lessing, B. (2016). Inside Out: The Challenge of Prison-Based Criminal Organizations. ( $\left.1^{\mathrm{a}} \mathrm{ed}.\right)$. Washington, DC: Brookings Institution.

Looft, C. (29 de mayo de 2012). Knights Templar Raise Stakes, Target Big Business. Insight Crime Organized Crime in the Americas. Recuperado de http://www.insightcrime.org/ news-briefs/knights-templar-raise-stakes-extort-big-business

Maihold, G. (2011). Las comunicaciones criminales: el caso de las Narcomantas. En BenítezManaut, R. (Ed.). Crimen organizado e Iniciativa Mérida en las Relaciones MéxicoEstados Unidos (1 $1^{\text {a }}$ ed., pp. 83-91). México, D.F.: Colectivo de Análisis de la Seguridad con Democracia (CASEDE).

Maldonado, S. (14 de enero de 2014). Michoacán y las autodefensas: ¿Cómo llegamos aquí? Nexos. Recuperado de http://redaccion.nexos.com.mx/?p=6011

Manwaring, M. (1 de julio de 2008). Sovereignty under siege: Gangs and other Criminal Organizations in Central America and Mexico. Air \& Space Power Journal. Recuperado de http://www.au.af.mil/au/afri/aspj/apjinternational/apj-s/2008/2tri08/ manwaringeng.htm

Martínez, E. (1 de junio de 2012). Caballeros templarios se atribuyen los ataques a Sabritas en Michoacán. La Jornada. Recuperado de http://www.jornada.unam.mx/2012/06/01/ politica/015n2pol

Metz, S. (2012). The future of insurgency. ( $1^{\text {a }}$ ed.). Carlisle Barracks, PA: Strategic Studies Institute, U.S. Army War College.

Nájar, A. (9 de mayo de 2013). Michoacán, el reino narco de Los Caballeros Templarios. BBC Mundo. Recuperado de http://www.bbc.com/mundo/noticias/2013/05/130509_ michoacan_reino_caballeros_templarios_mexico_narcotrafico_an

OAS. (2015). Searching for Common Approaches to Deal with Unconventional Conflicts and Violence in the Americas. ( $1^{\text {a }}$ ed.). Washington, DC: Secretariat for Multidimensional Security.

ONUDD. (2004). Convención de las Naciones Unidas contra la delincuencia organizada transnacional. ( $1^{\text {a }}$ ed.). Viena: Oficina de Naciones Unidas contra la Droga y el Delito (ONUDD). 
Pérez Caballero, J. (2015). El elemento político en los crímenes contra la humanidad. (1 $1^{\text {a }}$ ed.). Madrid: Dykinson.

Phillips, B. (2015). How Does Leadership Decapitation Affect Violence? The Case of Drug Trafficking Organizations in Mexico. The Journal of Politics, 77(2), 324-336.

Plant, K.y Dudouet, V.(2015). Fit fornegotiation? Options and risks in the political transformation of non-conventional armed groups. ( $1^{\text {a }}$ ed.). Oslo: Norwegian Peacebuilding Resource Centre (NOREF).

PNUD. (2015). Índice de Desarrollo Humano para las entidades federativas, México 2015: Avance continuo, diferencias persistentes. ( ${ }^{a}$ ed.). México, DF: Programa de las Naciones Unidas para el Desarrollo (PNUD).

Prados, L. (2 de junio de 2012). "El narco es una insurgencia criminal contra el Estado". El País Internacional. Recuperado de http://internacional.elpais.com/ internacional/2012/06/02/actualidad/1338590616_688585.html

Proceso. (26 de julio de 2013). “Todo detonó cuando el narco abusó de nuestras esposas e hijas". Proceso. Recuperado de http://www.proceso.com.mx/?p=348474

Ramsey, G. (14 de septiembre de 2012). Las Maras de El Salvador buscan ser actores políticos. Insight Crime Crimen Organizado en las Américas. Recuperado de http:// es.insightcrime.org/investigaciones/las-maras-de-el-salvador-buscan-ser-actorespoliticos

Rodríguez, O. (2015). El limbo democrático: Estado de Derecho, crimen organizado y paramilitarismo en México. Politai: Revista de Ciencia Política, 6(11), 15-32.

Romero, V. y Díaz-Cayeros, A. (2014). Living in fear: The dynamics of extortion in Mexico's criminal insurgency. ( $1^{\mathrm{a}}$ ed.). Stanford: Center on Democracy, Development and Rule of Law (CDDRL)-Law Freeman Spogli Institute for International Studies Stanford University.

Sánchez Escobar, C. (2015). Crimen organizado, tráficos ilícitos y corrupción. En Aznar F. y Ramos, M. (Eds.). Vulnerabilidad y Democracia en Iberoamérica (1ª ed., pp. 97-145). Valencia: Tirant lo Blanch.

190 Si Somos Americanos. Revista de Estudios Transfronterizos 
Schedler, A. (2013). Mexico’s Civil War Democracy. (1 ${ }^{\mathrm{a}}$ ed.). México, DF: Centro de Investigación y Docencia Económicas (CIDE).

Schedler, A. (2014). The Criminal Subversion of Mexican Democracy. Journal of Democracy, 25(1), 5-18.

Sohr, R. (2015). El Terrorismo Yihadista. (1ª ed.). Santiago: Debate.

Sullivan, J. (2012). From Drug Wars to Criminal Insurgency: Mexican Cartels, Criminal Enclaves and Criminal Insurgency in Mexico and Central America. (1 $1^{\text {a }}$ ed.). Washington, DC: Fondation Maison des sciences de l'homme.

Sullivan, J. y Elkus, A. (16 de agosto de 2010). Strategy and insurgency: an evolution in thinking? Open Democracy. Recuperado de https://www.opendemocracy.net/john-psullivan-adam-elkus/strategy-and-insurgency-evolution-in-thinking

Tabory, S. (26 de abril de 2016). El Salvador clasifica pandillas como terroristas y penaliza negociaciones. Insight Crime Crimen Organizado en las Américas. Recuperado de http://es.insightcrime.org/noticias-del-dia/el-salvador-reforma-clasificacionpandillas-como-terroristas-penaliza-negociaciones

Trejo, G. y Ley, S. (1 de febrero de 2015). Municipios bajo fuego (1995-2014). Nexos. Recuperado de http://www.nexos.com.mx/?p=24024

Valdés, G. (2013). Historia del narcotráfico en México. (1 $1^{\text {a }}$ ed.). México, DF: Aguilar.

Yagoub, M. (11 de junio de 2014). ¿Está el nuevo presidente de El Salvador enterrando la tregua entre pandillas? Insight Crime Crimen Organizado en las Américas. Recuperado de http://es.insightcrime.org/noticias-del-dia/nuevo-presidente-el-salvador-enterrandotregua-entre-pandillas 